University of Nebraska - Lincoln

DigitalCommons@University of Nebraska - Lincoln

Faculty Publications, Department of Psychology

Psychology, Department of

$1-21-1993$

\title{
Long-Term Consequences of Childhood Physical Abuse
}

Robin Malinosky-Rummell

West Virginia University, robin@rumskytravelworks.com

David J. Hansen

Univertsity of Nebraska-Lincoln, dhansen1@unl.edu

Follow this and additional works at: https://digitalcommons.unl.edu/psychfacpub

Part of the Psychiatry and Psychology Commons

Malinosky-Rummell, Robin and Hansen, David J., "Long-Term Consequences of Childhood Physical Abuse" (1993). Faculty Publications, Department of Psychology. 99.

https://digitalcommons.unl.edu/psychfacpub/99

This Article is brought to you for free and open access by the Psychology, Department of at DigitalCommons@University of Nebraska - Lincoln. It has been accepted for inclusion in Faculty Publications, Department of Psychology by an authorized administrator of DigitalCommons@University of Nebraska - Lincoln. 
Published in Psychological Bulletin 114:1 (1993), pp. 68-79. Copyright (C) 1993 by the American Psychological Association, Inc. Used by permission. “This article may not exactly replicate the final version published in the APA journal. It is not the copy of record.” Journal homepage: http://www.apa.org/journals/bul/

Submitted October 1991; revised November 1992; accepted November 1992.

\title{
Long-Term Consequences of Childhood Physical Abuse
}

\author{
Robin Malinosky-Rummell, West Virginia University \\ David J. Hansen, University of Nebraska —Lincoln
}

\begin{abstract}
This article reviews the literature on the long-term consequences of childhood physical abuse. Empirical research is discussed within 7 topic areas: aggressive and violent behavior, nonviolent criminal behavior, substance abuse, self-injurious and suicidal behavior, emotional problems, interpersonal problems, and academic and vocational difficulties. The studies reviewed involve primarily adult populations, although pertinent findings from literature on children and adolescents are briefly summarized. Some variables that affect the relation between physical abuse and long-term consequences are examined. These moderator variables include maltreatment characteristics, individual factors, family factors, and environmental factors. The article ends with suggestions for future research on long-term consequences and variables that may affect these outcomes.
\end{abstract}

The widespread prevalence of child physical abuse, as well as the numerous problems and consequences associated with it, has been increasingly recognized since Kempe and his colleagues first described the symptoms of "the battered child syndrome" (Kempe, Silverman, Steele, Droegemueller, \& Silver, 1962). Although much of the research in recent decades has been on the behavior and treatment of the abusive parent as the perpetrator of the violent act, significant attention has also focused on the consequences of abuse, especially the immediate or short-term effects (cf. Ammerman, Cassisi, Hersen, \& Van Hasselt, 1986; Conaway \& Hansen, 1989; Hansen, Conaway, \& Christopher, 1990; Lamphear, 1985).

Physical abuse is generally defined as the presence of a nonaccidental injury resulting from acts of commission by an adult (Kelly, 1983). These acts are characterized by overt physical violence or excessive punishment (including poisoning and exposing to extreme heat or cold) and typically occur in discrete, low-frequency episodes (Kelly, 1983; Wolfe, 1988). In addition, physical abuse is often accompanied by parental anger toward the child that is due to the child's failure to meet parental demands (Abrams, 1981; Kelly, 1983). In a recent and extensive epidemiological study, the National Center on Child Abuse and Neglect (NCCAN; 1988) defined physical abuse as acts of commission that involve either demonstrable harm or endangerment to the child. Results indicated that in 1986 approximately 5.7 American children per 1,000 (for a total of 358,300 children) experienced physically abusive acts. Because this finding involved only those abusive instances reported to child protection services and other agencies, it probably underestimated the true incidence of physical abuse. The study also found that the rate of reported physical abuse increased by $58 \%$ over its 1980 level, which was most likely a result of increased public recognition of abuse rather than an increase in the actual occurrence of physical abuse (NCCAN, 1988).

The majority of research on the consequences of physical abuse has focused on short-term effects on childhood behavior. A variety of potential short-term consequences of physical abuse have been identified, such as greater perceptual-motor deficits, lower scores on measures of general intellectual functioning and academic achievement, negative social behavior such as more aggression with adults and peers, and internalizing psychological problems such as hopelessness, depression, and low self-worth (cf. Ammerman et al., 1986; Conaway \& Hansen, 1989; Fantuzzo, 1990; Lamphear, 1985). The longterm consequences of childhood physical abuse have not been as thoroughly explored, although such a review on the longterm consequences of childhood sexual abuse has been published (Browne \& Finkelhor, 1986). Because different forms of maltreatment (e.g., physical abuse, sexual abuse, and neglect) may lead to diverse short- and long-term consequences, it is important to investigate the effects of each (Conaway \& Hansen, 1989).

In this article, we review empirical research that investigated the long-term consequences of physical abuse. First, we describe research strategies that have been used to examine this issue. This research is primarily correlational in nature; therefore, causal relationships cannot be identified with confidence (Conaway \& Hansen, 1989). Hence, the term long-term consequences refers to characteristics of people having been physically abused as children, not to known causal relations. Although a variety of techniques have been used to examine this issue, this article primarily reviews studies that used comparison groups or other control procedures as opposed to simple descriptions or clinical case studies. Differences identified through these group comparisons were based on statistical analyses and therefore did not necessarily reflect clinically significant group differences. When the descriptions of the studies permit, the clinical significance of the effects are described.

Second, the long-term consequences are reviewed within seven domains. This review focuses primarily on studies of 
adult populations. Although long-term consequences may manifest themselves in adolescence or adulthood, the timing of the abuse in relation to the consequences assessed is not examined in most studies. In fact, for some children, the abuse may be ongoing throughout the study. In adults, it is assumed that the physical abuse experienced as a child has terminated, or at least that the developmental status of the child has changed. Within the topic areas, literature involving youths who are age 13 or older is briefly described to provide a context for the adult literature and to suggest behaviors that should be examined in future research with adults.

Third, moderator variables that affect the relation between physical abuse and long-term effects are reviewed. The identification of potential consequences and moderating influences provide a variety of directions for future research.

\section{Research Strategies Used in the Physical Abuse Literature}

Three types of research strategies have been used to explore the relationship between child physical abuse and later behavior: (a) comparison of rates of abuse history in two or more samples that differ on a behavior(s), (b) comparison of the behavior(s) of a group with a history of abuse with the behavior(s) of a nonabused group(s), and (c) prospective designs that assess behaviors of an at-risk or community sample at two or more different points in time. Advantages and disadvantages of each strategy are briefly reviewed below.

The first strategy involves the comparison of rates of a history of abuse in two or more samples that differ on a possible consequence of abuse (e.g., maltreating vs. nonmaltreating mothers or violent vs. nonviolent adults). This strategy does not control for the innumerable other variables that may also be influential (e.g., other familial stressors); thus, studies involving this type of research design are deemphasized in this review. To control for these additional variables, some studies use samples that are matched on one or more variables.

The second strategy involves comparing the behavior of subjects with a history of physical abuse with the behavior of comparison groups, on the assumption that the differences in their behavior may be a consequence of the abuse. For example, several studies compared the behavior of physically abused subjects with nonabused subjects within a particular type of population, such as people with substance abuse problems. Findings from this type of research are difficult to generalize to other physically abused populations, such as those who do not have a substance abuse problem. To eliminate this issue, research with physically abused subjects also uses abused or nonabused comparison groups from the community. Matching procedures and statistical techniques (e.g., covariance or multiple regression analyses) are used to control for or consider variables other than physical abuse that may also affect the behaviors assessed (e.g., Briere \& Runtz, 1988).

These first two research strategies are retrospective in that data are collected after the abuse took place. Therefore, neither of these correlational strategies can demonstrate a definite causal relationship between physical abuse and later outcomes. Furthermore, retrospective self-reports may involve biases that are due to distortion, lack of memory about such events, and other reporting issues. Such potential biases may be reduced through the use of archival data (involving child protective services, court, medical, and psychiatric records) that corroborate these self-reports. However, archival data alone may include only officially reported instances of abuse and thus underrepresent the occurrence of abuse. The information in the archival records generally has not been systematically collected and consequently may vary due to reporting agents and procedures. Because of these methodological problems, research involving exclusively archival data is discussed only briefly in this review.

The third strategy involves prospective designs. Two types of prospective studies have been used to avoid problems associated with retrospective data collection. First, McCord (1979, 1983) used 232 boys with similar socioeconomic status (SES) in her treatment study that was designed to prevent juvenile delinquency. On the basis of observations of the boys and their families made by social work counselors, McCord divided subjects into four groups according to how they were treated by their parents (abused, neglected, rejected, and loved). She then obtained archival data on these boys over a 30-year period. This study was therefore prospective in the sense that she made an initial assessment before the occurrence of the longterm consequences that were examined. However, causal relationships between physical abuse and later consequences could not be estimated because McCord did not experimentally manipulate the groups nor did she control for variables other than SES that might have influenced her dependent measures. Second, some researchers (Egeland, 1988; Egeland, Jacobvitz, \& Sroufe, 1988) obtained data from parents of high-risk infants before and after incidents) of physical abuse. Although these authors did not specifically examine consequences of the abuse on the infants, an experimental design that utilizes this prospective strategy can be utilized to estimate causal relationships between physical abuse and long-term consequences.

The retrospective and prospective designs collect different information, and the retrospective methodology may appear to demonstrate a stronger link to physical abuse than actually exists (Widom, 1989). For example, Hunter and Kilstrom (1979), using a prospective design, interviewed 282 new mothers who had not yet had the opportunity to abuse their newborn and found that 49 of the mothers had been physically abused as a child. The researchers collected data 1 year later and found that 10 of the 282 mothers had maltreated their babies, and of these 10 maltreating mothers, 9 had reported being abused as a child. The prospective research design found that only 9 out of $49(18 \%)$ mothers with a history of abuse had maltreated their babies within a year. If this research had been conducted retrospectively, the results could have indicated that 9 out of 10 (90\%) maltreating mothers were abused as a child, suggesting a stronger association between child physical abuse and adult perpetration than indicated by the prospective methodology. Thus, although a high percentage of the sample of interest may have been physically abused, not many physically abused people may demonstrate such an outcome.

\section{Research on Long-Term Consequences}

On the basis of the literature, research on the long-term con- 
sequences of physical abuse is reviewed within seven topic areas: aggressive and violent behavior, nonviolent criminal behavior, substance abuse, self-injurious and suicidal behavior, emotional problems, interpersonal problems, and academic and vocational difficulties. Only studies that concern physical abuse are included. Research involving other forms of maltreatment are briefly reviewed where several types of maltreatment, including physical abuse, are grouped together.

\section{Aggressive and Violent Behavior}

The majority of literature on the long-term consequences of physical abuse explores aggressive and violent behaviors in adolescents and adults. This research can be divided into five categories: adolescent violence, and adult violence toward nonfamilial persons, toward children, toward dating partners, and toward spouses.

Adolescent violence. Findings that are based on three types of research methodologies support the strong link between physical abuse and adolescent aggression (cf. reviews by Garbarino \& Plantz, 1986; Lane \& Davis, 1987). First, adolescents who exhibit aggressive and violent behaviors, including extrafamilial and dating violence, demonstrate higher rates of maltreatment than do the general population (Alfaro, 1981; Garbarino \& Plantz, 1986; Roscoe \& Callahan, 1985). Second, violent adolescent boys in residential facilities demonstrate higher rates of physical abuse than do less violent and nonviolent male comparison groups, on the basis of archival research (Lewis et al., 1985; Lewis, Shanok, \& Balla, 1979; Lewis, Shanok, Pincus, \& Glaser, 1979; Sendi \& Blomgren, 1975). High school students who are involved in dating violence report higher rates of physical abuse than do nonviolent students (Reuterman \& Burcky, 1989). Third, among children who are receiving mental health treatment, those who have been physically abused exhibit more aggressive behavior than do their nonabused peers (e.g., Blount \& Chandler, 1979; Cavaiola \& Schiff, 1988; Kent, 1976; Monane, Leichter, \& Lewis, 1984; Tarter, Hegedus, Winsten, \& Alterman, 1984). This finding may be true for boys only, however (Rogeness, Amrung, Macedo, Harris, \& Fisher, 1986). Recent conceptualizations also note that central nervous system injury and psychosis are associated with violence in abused adolescents (Lewis, Mallouh, \& Webb, 1989; Lewis et al., 1985).

Adult violence toward nonfamilial persons. Research comparing rates of physical abuse in violent and nonviolent adults through questionnaire data supports a relationship between physical abuse and violence toward nonfamilial persons. For example, Sack and Mason (1980) found that convicted male felons, particularly those who had committed sexual offenses, reported much higher rates of childhood physical abuse than did noninstitutionalized males. M. Rosenbaum and Bennett (1986) also revealed that homicidal, depressed male and female outpatients reported higher rates of physical abuse than did a nonhomicidal, depressed sample who were matched on sex, age, and marital status. In contrast, another study of this kind (Tupin, Mahar, \& Smith, 1973) did not reveal a significant difference in the rates of physical abuse among habitually violent, nonhabitually violent, and nonviolent male offenders. The authors looked at paternal physical aggression, which may have included non- abusive physical aggression such as spankings. This type of punishment may not have the emotional or physical impact on a child that abusive parental discipline would inflict.

Although rates of physical abuse may differ between violent and nonviolent adult populations, questionnaire data obtained by Gully, Dengerink, Pepping, and Bergstrom (1981) also indicated that rates of parental aggression (which may have included nonabusive physical punishment) might not differ between college students who self-reported engaging in violence and those who did not. Subjects' reported aggression toward their siblings did significantly discriminate between these groups, however. Additional multiple regression analyses indicated that reported parental violence toward subjects and toward spouses, as well as reported viewing and engaging in sibling violence, demonstrated a significant positive relationship with self-reported violence.

Overall, these findings imply that violent inmates and outpatients, particularly males, report higher rates of childhood physical abuse than do less violent comparison groups. Violent inmates and college students do not report higher rates of parental aggression, which may include nonabusive punishment, than do less violent persons. Additionally, parental spouse abuse and witnessing or engaging in sibling violence, may also contribute to extrafamilial violence in college students. Findings that were based on these self-reported data would have been strengthened with corroborating ratings by others or existing records of aggressive behavior.

Researchers have compared levels of violent behaviors demonstrated by abused and nonabused subjects through retrospective chart reviews. Using recorded data obtained during therapy of patients hospitalized for alcoholism treatment, Kroll, Stock, and James (1985) found that physically abused adult male alcoholics demonstrated significantly more legal difficulties (primarily bar brawls) and more violence against authority figures than did nonabused comparison groups who were matched on age, marital status, education, employment, occupational level, and drinking pattern. Additional research using a similar methodology with adolescent and adult inpatients also supports these findings (Carmen, Rieker, \& Mills, 1984; Mills, Rieker, \& Carmen, 1984). Thus, physically abused persons, especially males, demonstrate more violence toward others than do non-abused subjects.

Some authors have used a correlational approach to evaluate the relationship between childhood physical abuse and violence against others. Using a multiple regression design, Pollock et al. (1990) interviewed 201 men with alcoholic fathers in 19791980 as a part of a different cohort study. Results indicated that after controlling for parental alcoholism, self-reported abuse predicted aggression toward others including fighting and violent criminal acts. Using canonical analyses, Briere and Runtz (1990) administered questionnaires that they had constructed to 251 university women. They found that childhood physical abuse was linked to aggression toward others. Yesavage et al. (1983) evaluated 100 schizophrenic inpatients with a childhood discipline questionnaire and an observational measure of ongoing aggressive behavior. They found that a history of severe discipline, particularly paternal discipline, and parental conflict in childhood was positively correlated with ongoing observed inpatient assaults and other dangerousness measures in these inpatients. Although these data indicate that parental aggression and 
physical abuse appear to be related to later aggressive behavior toward nonfamilial persons in males and females, the biases inherent in the self-report measures render their validity questionable, particularly when used with schizophrenic inpatients.

Finally, McCord (1983) explored the relationship between physical abuse and later violent behavior in her aforementioned prospective study She did not find a difference among abused, neglected, rejected, and loved groups on the overall rate of crimes committed in adulthood (McCord, 1983). Violent crimes were not discriminated from other types of crimes in this analysis. Subsequent multiple regression analyses revealed that lack of supervision, parental conflict, and parental aggression, including physical abuse, accounted for a significant amount of the variance in "personal crimes" (e.g., assault, rape, and murder). Therefore, parental aggression has a positive relationship with violent criminal behavior.

Adult violence toward children. In addition to nonfamilial violence, several investigations examined patterns of familial violence in adults with histories of childhood physical abuse. Because other authors (Kaufman \& Zigler, 1987; Widom, 1989) recently reviewed research on the intergenerational transmission of abuse, the findings are only briefly mentioned here. Estimates of intergenerational transmission of abuse range from $7 \%$ to $70 \%$, depending on the research methodology used. Reviewers (Kaufman \& Zigler, 1987; Widom, 1989) agree that approximately one third $(30 \% \pm 5 \%)$ of physically abused or neglected individuals abuse their own children. Perpetration of abuse by these individuals may be moderated by aspects of their childhood maltreatment, their social relationships, cognitive and emotional factors, and current stressors (Egeland, 1988; Egeland et al., 1988; Herrenkohl, Herrenkohl, \& Toedter, 1983; Hunter \& Kilstrom, 1979).

Adult violence toward dating partners. Studies that used several different self-report methodologies demonstrate a relationship between childhood physical abuse and dating violence in college students. Laner and Thompson (1982) found that college students with a history of abuse had received higher rates of dating violence than had nonabused students. Abused subjects also inflicted higher rates of dating violence than did nonabused subjects. Similarly, Bernard and Bernard (1983) found that males and females who had inflicted dating violence reported significantly higher rates of experienced or observed physical abuse in their families of origin than did nonabusive subjects. Furthermore, approximately $75 \%$ of abusive subjects used the same form of violence on their dating partners as they had experienced or observed in childhood. However, neither study controlled statistically for additional variables that might affect dating violence.

A few studies have conducted correlational and multiple regression analyses to predict dating violence in college students. Riggs, O'Leary, and Breslin (1990) found that physical abuse, as well as parental marital violence and life events, significantly correlated with inflicted dating violence in male and female college students. Another study (Sigelman, Berry, \& Wiles, 1984) discovered gender differences in that childhood physical abuse, as well as low social desirability scores, predicted both received and inflicted dating violence for women but not for men.

Similarly, Marshall and Rose (1990) found that childhood physical abuse predicted received and inflicted dating violence for women but that this relationship was less strong for men. Positive stress, or the total reported impact of recent positive life events, predicted inflicted dating violence in men only. In contrast, an earlier study by Marshall and Rose (1988) revealed that childhood abuse among men significantly predicted received and inflicted dating violence, whereas childhood abuse among women predicted received violence. The results of these studies may have differed because of definitional variations. Both studies by Marshall and Rose $(1988,1990)$ included Conflict Tactics Scales (CTS) items of verbal and physical aggression in their definitions of childhood abuse and dating violence, whereas Sigelman et al. (1984) included only CTS physical aggression items. Riggs et al. (1990) developed a three-item measure of childhood physical abuse that included physical aggressiveness only. Additionally, Marshall and Rose (1988) included married subjects and thus examined dating and marital violence, whereas the other three studies did not. Thus, although childhood physical abuse appears to predict dating violence in college students, the relationship is relatively weak and appears to be influenced by a variety of other factors, including gender differences and parental marital violence.

Adult violence towards spouses. Descriptive data from several sources (e.g., Fitch \& Papantonio, 1983; Roscoe \& Benaske, 1985; Straus, Gelles, \& Steinmetz, 1980) suggest that physical abuse relates to inflicted and received marital violence for both males and females, even after controlling for parental marital violence. For example, Straus et al. (1980) surveyed 1,146 American homes. Of men whose parents did not hit each other, those who had been physically abused as teenagers had twice the rate of violence toward their wife than did nonabused men. This relationship was less strong for women. Unfortunately, these studies did not report tests for statistical significance between abused and nonabused groups; many also did not report attempts to control for additional variables, such as parental marital violence, that may have discriminated between groups.

Kalmuss (1984) intervieweda nationally representative sample of 2,143 adults. Through chi-square analyses, she found that both physical abuse in adolescence and parental marital violence were significantly related to inflicting severe marital violence for both men and women. However, parental marital violence was more strongly related than physical abuse to marital violence. Because earlier physical abuse in childhood was not assessed, however, the incidence of physical abuse was probably underestimated and consequently may have a stronger relationship to marital violence than reported.

Two studies using control groups have been conducted on male perpetrators of marital violence. First, Kroll et al. (1985) discovered that physically abused alcoholic men described significantly more marital violence toward their wife during treatment than did nonabused alcoholic comparison groups, on the basis of retrospective chart reviews. Problems with this study involved biases related to archival data and the limited generalization of findings to nonalcoholic men. Second, A. Rosenbaum and O'Leary (1981) administered questionnaires to abusive couples (i.e., the husband had committed at least one abusive act) and to nonviolent, maritally discordant couples who were receiving psychological treatment, as well as to satisfacto- 
rily married couples in the community. No differences between groups on age, years married, or religion existed. On the basis of both husband and wife reports, A. Rosenbaum and O'Leary found that abusive husbands had experienced significantly more physical abuse and, especially, parental marital violence than had nonabusive husbands. Additionally, husband and wife reports revealed that the rate of childhood abuse experienced by abused wives did not differ from that experienced by nonabused wives. These findings imply that whereas childhood physical abuse relates to spouse abuse in men, it may not relate to women's involvement in abusive marital relationships. Furthermore, parental marital violence may also contribute to spouse abuse.

\section{Nonviolent Criminal Behavior}

Physically abused children demonstrate significantly more noncompliance, nonaggressive conduct disorders, and other externalizing behaviors than do nonabused comparison groups (cf. Ammerman et al., 1986; Conaway \& Hansen, 1989; Hansen et al, 1990; Kashani, Shekim, Burk, \& Beck, 1987; Lamphear, 1985; Rogeness et al, 1986). Similarly, research on juvenile delinquency reveals that physically abused adolescents demonstrate more legal problems than do nonabused comparison groups (cf. Alfaro, 1981; Cavaiola \& Schiff, 1988; Garbarino \& Plantz, 1986; Lane \& Davis, 1987; Pfouts, Schopler, \& Henley, 1981). Because violent and nonviolent crimes are often combined in these delinquency studies, however, it is unclear if physically abused adolescents engage in more nonviolent criminal behavior than do nonabused peers. Additionally, the behavior of physically abused children may appear similar to child witnesses of domestic violence (Jaffe, Wolfe, Wilson, \& Zak, 1986) and children from nonabusive families who experience parent-child problems (Wolfe \& Mosk, 1983). Although these findings imply that family variables such as spousal violence and parent-child relationship problems also impact externalizing behaviors, family variables frequently are not controlled for in the aforementioned literature.

Two studies using multiple regression analyses have explored the relationship between childhood physical abuse and nonviolent criminal behavior in adults. Through data collected during interview, Pollock and associates (Pollock et al, 1990) demonstrated that after they controlled for parental alcoholism, self-reported physical abuse predicted criminal acts, including traffic offenses, theft, or sexual and violent crimes. This study revealed problems that were similar to those found in the delinquency literature, because the authors did not discriminate between violent and nonviolent criminal acts in their analysis nor did they control for family variables. McCord's (1979) prospective research addressed these problems through multiple regression analyses; subject's home environment, nonviolent crimes, and violent crimes were measured independently and were controlled through statistical analyses. McCord did not discriminate physical abuse from other parental aggression, however. She discovered that lack of maternal affection and supervision and paternal "deviation" (i.e, alcoholism or conviction of a serious crime) contributed significantly to the variance in property crimes (e.g., larceny, auto theft, and breaking and entering), but parental aggression, including physical abuse, did not. Therefore, present research has not shown a relationship between physical abuse and nonviolent criminal behavior.

\section{Substance Abuse}

Some evidence exists to support a relationship between childhood physical abuse and substance abuse in adolescence. Cavaiola and Schiff (1988) conducted a retrospective chart review of 500 adolescent subjects who had been admitted to a residential treatment program. They found that $30 \%$ of their subjects had been physically or sexually abused, a higher rate than that in the general population. They also found that abused adolescents had begun alcohol and drug abuse at an earlier age than had nonabused substance abusers in the same program, as well as nonabused, nonchemically dependent adolescents in the community. Additionally, the authors noted a high rate of parental substance abuse (75\%) reported by the abused group, a finding supported by other research on adolescent inpatients (Carmen et al, 1984); however, they did not control for the possible effects of parental substance abuse on subjects' substance abuse. Because the authors grouped sexual-and physical-abuse victims together, the relationship between substance abuse and physical abuse only was unclear.

Adults who abuse substances report a higher incidence of childhood physical abuse than that reported by the general population, with estimates ranging from $13 \%-35 \%$, depending on the type of data collection used (Cohen \& DensenGerber, 1982; Kroll et al, 1985; Schaefer, Sobieraj, \& Hollyfield, 1988). Comparisons of substance abuse in abused versus nonabused adult samples yield mixed reviews, however. Using self-report questionnaires, Schaefer etal.(1988)compared drinking behaviors in physically abused male alcoholic veterans and non-abused alcoholic veterans who demonstrated similar race, religion, income, and treatment variables. They found that abused alcoholics did not differ from nonabused alcoholics in the onset, severity, or treatment history of alcoholism. Physically abused subjects did report that alcohol had a stronger impact on their life-style, activities, and social interactions than did nonabused comparison groups. Using a retrospective chart review, Kroll et al. (1985) discovered that physically abused alcoholic men demonstrated significantly more "suicidal drinking" (drinking despite serious medical conditions such as liver failure) than did nonabused comparison groups. These studies indicate that physically abused male alcoholics report more problematic drinking behaviors, accompanied by life-style, social, and medical difficulties, than do nonabused alcoholics. These findings cannot be generalized to women and nonalcoholic populations, however; and, again, parental substance abuse was not adequately controlled.

Comparisons of abused and nonabused groups in inpatient and community settings also reveal differences in drinking-related issues. Through intake interviews to a military medical center, Brown and Anderson (1991) discovered that physically abused inpatients and inpatients with combined physicalabuse and sexual-abuse histories had higher rates of alcoholuse disorders and histories of alcohol and drug abuse than did non-abused inpatients. Although the authors noted that physi- 
cally abused men reported higher rates of parental alcoholism than did nonabused men, they did not control for the effects of parental alcoholism or the effects of other variables (e.g., SES) on inpatients' alcohol-related behaviors. Results from prospective research indicated that physically abused men did not show higher rates of alcoholism than did men from neglected, rejected, and loved backgrounds (McCord, 1983). Parental alcoholism did negatively affect subjects' vulnerability to negative outcomes of abuse, which included alcoholism. The research indicates that physically abused inpatients tend to experience more alcoholism disorders and drug and alcohol abuse than do nonabused inpatients. Furthermore, abused populations also demonstrate higher rates of parental alcoholism, a variable that has not been adequately controlled in most studies. Researchers describing the link between childhood physical abuse and adult substance abuse suggest that the stronger tendency to abuse substances is a result of abuse-related feelings and cognitions (e.g., Brown \& Anderson, 1991; Kroll et al., 1985; Sehaefer et al., 1988).

\section{Self-Injurious and Suicidal Behavior}

Maltreatment has been linked to adolescent self-injurious and suicidal behaviors in studies using two different types of methodologies. Archival research has shown that groups of sexually or physically abused adolescents demonstrate more suicidal ideation and attempts than do nonabused comparison groups (Cavaiola \& Schiff, 1988; Deykin, Alpert, \& McNamarra, 1985). Isolating physical abuse as the variable of interest, Rogers and LeUnes (1979) examined the records of 52 subjects who had been institutionalized for a variety of criminal offenses. They found no difference in suicide attempts among physically abused, institutionalized adolescents in comparison with nonabused peers, perhaps because they only examined suicidal attempts that occurred during a 6-month period. Although these results cannot be generalized to nondelinquent adolescents, they suggest that physical abuse alone may not be related to suicidal behavior in teens. Archival research with adolescent and adult psychiatric inpatients supports this notion, in that victims of both physical and sexual abuse were more likely to exhibit suicidal behavior than were victims of either sexual or physical abuse alone (Carmen et al., 1984; Mills et al., 1984). Additional research to understand the gender and age differences in the effects of physical abuse is needed.

A retrospective chart review by Kroll et al. (1985) constitutes the only comparison of suicidality in abused and nonabused groups. These authors found that physically abused alcoholic men demonstrated a higher incidence of serious suicide attempts than did nonabused comparison groups matched on age, marital status, education, employment, occupational level, and drinking pattern. Although these results demonstrate a relationship between childhood physical abuse and suicidality in men, the authors did not control for factors such as parental substance abuse, nor can the results be generalized to nonalcoholic populations.

Several researchers have used self-report questionnaires and multiple regression analyses with inpatient and college populations, to further explore the relationship between childhood physical abuse and self-destructive behavior. First, Bryer,
Nelson, Miller, and Krol (1987) found that physical or sexual abuse accounted for a significant amount of the variance in suicidal ideation, gestures, and attempts in female inpatients. Similarly, physical abuse and parental conflict accounted for $44 \%$ of the variance in self-destructive acts performed by depressed male inpatients (Yesavage \& Widrow, 1985). Not only are these findings limited to inpatient populations, who may not be reliable informants, but the former study includes both physical and sexual abuse in the abuse group, whereas the latter includes both physical abuse and parental conflict in the reported analyses. Briere and Runtz (1988) addressed these difficulties in their research by specifically focusing on physical abuse in college women. They discovered that self-reported physical abuse by mother was associated with increased suicidal ideation. Thus, physical abuse appears to be related to self-injurious and suicidal behaviors in male and female inpatients, as well as in female college students. Gender, form of maltreatment, and parental conflict may also affect this relationship.

\section{Emotional Problems}

Physically abused youths who are 6 to 16 years old and children from violent or distressed families display significantly more emotional problems, including anxiety and depression, than do nonabused community children (Hjorth \& Ostrov, 1982; Jaffe et al., 1986; Wolfe \& Mosk, 1983). Additionally, regression analyses with 7 - to 17-year-old youths revealed that a history of maltreatment accounted for $58 \%$ of the variance in schizoid disorder as measured by the Diagnostic Interview for Children and Adolescents (Kashani et al., 1987). Whereas abused youths appear to have more emotional problems than do nonabused children, family variables such as marital violence and parent-child interaction difficulties may also contribute to these problems (cf. reviews by Ammerman et al., 1986; Hansen et al., 1990).

Two studies used the self-report Symptom Checklist90- Revised (SCL-90-R) to measure psychiatric symptoms in abused and nonabused inpatient adults. First, Chu and Dill (1990) found that physically abused, female inpatients obtained higher scores on SCL-90-R subscales of Anxiety, Hostility, Paranoid-Ideation, and Psychoticism, as well as on the Dissociative Experiences scale, than did nonabused, female inpatients. Second, Bryer et al. (1987) found that physically abused, female inpatients demonstrated higher on scores SCL-90-R subscales of Depression, Phobic Anxiety, Anxiety, Somatization, ParanoidIdeation, and Psychoticism than did nonabused inpatients. Furthermore, patients who had experienced both sexual and physical abuse had significantly higher mean SCL90-R scores than did patients with sexual- or physical-abuse histories only. These results demonstrate a relationship between childhood physical abuse and self-reported emotional problems in female inpatients; however, biases that are due to self-reported abuse histories by this population and limited generalization to other populations (e.g., men and outpatients) must be considered.

The limited generalization of the previous two studies has been addressed by research involving college women (Briere \& Runtz, 1988). Using an older version of the SCL-90-R, the Hopkins Symptom Checklist (HSC), Briere and Runtz showed that generalized parental abusiveness, including both psycho- 
logical and physical abuse, positively correlated with all HSC subscales and with a dissociation scale constructed by the authors. Multiple regression analyses also revealed that psychological maltreatment by fathers was related to anxiety, depression, and dissociation, whereas physical abuse by mothers was associated with dissociation. These results indicate that the contribution of psychological maltreatment must be controlled when examining emotional problems in adult populations. The relationship between physical abuse and dissociation has also been noted in research by Putnam, Guroff, Silberman, Barban, and Post (1986).

Studies involving substance abusers demonstrate a link between maltreatment histories and adult emotional problems in men. Through archival data, Kroll et al. (1985) found that physically abused alcoholic men showed more pervasive and situational anxiety than did nonabused alcoholics who were matched on several variables. Using questionnaires, Schaefer et al. (1988) determined that physically abused, alcoholic, male veterans obtained higher scores on all subscales of the SCL-90R (including Somatization, Depression, Anxiety, and Psychoticism) than did nonabused alcoholics who were similar in race, religion, income, and treatment variables. These studies therefore support a relationship between physical abuse and emotional problems in alcoholic men, but parental substance abuse was not adequately controlled.

In conclusion, physical abuse has been associated with a variety of emotional problems, including somatization, anxiety, depression, hostility, paranoid ideation, psychosis, and dissociation, in female inpatient and community samples. Findings suggest that this relationship may be moderated by aspects of the maltreatment, including the presence of multiple forms of maltreatment and gender of perpetrator. Physical abuse has shown a positive relationship with these emotional problems in alcoholic men, which limits the generalizability of these results to other populations. Additionally, statistical significance has been emphasized in these studies. Although some authors note the pervasiveness of more severe psychological distress - or, more specifically, depression and anxiety - in abused groups as compared with nonabused groups (Bryer et al., 1987; Kroll et al., 1985; Schaefer et al., 1988), the clinical or practical significance of these findings (e.g., differences in SCL-90-R scores between groups) has not been thoroughly explored, particularly in the college samples.

\section{Interpersonal Problems}

Research on peer relationships in maltreated children and adolescents show mixed findings (cf. reviews by Ammerman et al., 1986; Conaway \& Hansen, 1989; Lamphear, 1985). On the basis of parent and teacher reports, some research indicates that physically abused children demonstrate fewer social competencies than do nonabused community children (e.g., Kent, 1976; Wolfe \& Mosk, 1983), whereas other research did not find differences between these groups (e.g., Jaffe et al., 1986). Because Wolfe and Mosk (1983) discovered also that physically abused children and children with distressed family relationships did not differ in social competence, these difference might be accounted for by uncontrolled family variables (e.g., distress, parent-child conflict issues, and maltreatment history), as well as by different definitions of social competence.

Three studies used the SCL-90-R with physically abused adults to measure interpersonal sensitivity, that is, negative feelings about interpersonal interactions, such as feeling shy and self-conscious and feeling that one is not understood or is disliked. Two studies demonstrated that adult, female inpatients who reported childhood physical abuse had significantly higher interpersonal sensitivity scores than did unmatched groups of nonabused inpatients (Bryer et al., 1987; Chu \& Dill, 1990). Unfortunately, neither study controlled for variables other than physical and sexual abuse, which may have affected interpersonal scores (e.g., through matching procedures). Using multiple regression analyses, Briere and Runtz (1988) discovered that self-reported parental abusiveness positively correlated with college women's scores on the Interpersonal Sensitivity subscale of the HSC. More specifically, both maternal physical abuse and paternal psychological maltreatment significantly predicted higher interpersonal sensitivity in these subjects. Although the clinical significance of this finding remains unclear, Briere and Runtz (1988) noted that their effect sizes were large, as the predictors explained more than $20 \%$ of the variance in the dependent variables. Whereas these results indicate a relationship between childhood physical abuse and negative feelings about interpersonal relationships in adulthood, they also highlight the importance of controlling for the variance contributed by a history of psychological maltreatment when examining the relationship between physical abuse and interpersonal competency.

On the basis of her prospective data, McCord (1983) noted similar divorce rates for men from abused, neglected, rejected, and loved backgrounds. Thus, after important family and maltreatment variables are controlled, divorce rate does not appear to differ between abused and nonabused men.

\section{Academic and Vocational Difficulties}

Several studies indicate that maltreated children and adolescents are delayed intellectually and academically, on the basis of test performance (e.g., Kent, 1976; Rogeness et al., 1986; Tarter et al., 1984; also see reviews by Ammerman et al., 1986; Hansen et al., 1990; Lamphear, 1985). Furthermore, cognitive abilities may be affected by maltreatment factors. Neglected boys demonstrate significantly lower IQ scores than do physically abused and nonabused boys, whereas physically abused girls and neglected girls both display lower IQ scores than do nonabused groups (Rogeness et al., 1986).

It is therefore surprising that little research has been conducted on truancy and other academic difficulties in abused populations. On the basis of interviews that were conducted by social workers, Pfouts et al. (1981) noted that $40 \%$ of their adolescent observers and victims of family violence engaged in truancy, a relatively high truancy rate as compared with that of the general population. By means of a self-report questionnaire, Hjorth and Ostrov (1982) discovered that physically abused youths in a child protective facility were less oriented to future vocational and educational goals than were nonabused youths who were matched on age, gender, race, and area of residence. With archival data, Rogers and LeUnes (1979) did not find differences in school expulsions among physically abused and 
nonabused 14- to 18 -year-old institutionalized delinquents. The limited 6-month period for data collection, as well as the limited sample of adolescents, may also account for these findings. Discrepancies among studies may be due to differences such as variations in data collection, definition of academic problems, and research design.

Even less research on academic and vocational difficulties has been conducted with adult populations. In her prospective study, McCord (1983) indicated that men with abused, neglected, rejected, or loved backgrounds did not differ on occupational status or in proportions returning to school for further education. However, McCord (1983) stated that subjects who were less vulnerable to their parents' neglect or physical abuse "were more likely to have returned to school having once terminated their education" (p. 269). Adults with physical-abuse histories may differ on more fine-grained measures of vocational difficulties.

\section{Summary of Long-Term Consequences}

Research involving several different methodologies has demonstrated a strong relationship between physical abuse and nonfamilial and familial violence. Studies on nonfamilial violence show that violent persons report higher rates of physical abuse then do less violent comparison groups. Furthermore, retrospective and prospective data indicate that physically abused persons, especially males, demonstrate more violence than do nonabused subjects. In regard to familial violence, it is estimated that approximately $30 \%( \pm 5 \%)$ of physically abused or neglected individuals abuse their own children (Kaufman \& Zigler, 1987; Widom, 1989). Childhood physical abuse also predicts inflicting and receiving dating violence in college students. Last, spouse abusers report higher rates of physical abuse than do nonabusive spouses, and physically abused persons abuse their spouse more often than do nonabused persons.

Research on nonviolent criminal behavior in adolescence typically combines violent and nonviolent criminal behaviors into one category. These studies have shown that abused youths engage in more externalizing and criminal behaviors than do nonabused comparison groups. The limited research with adult subjects does not support an association between physical abuse and exclusively nonviolent criminal behavior.

Although physically abused persons may not differ from nonabused comparison groups in alcoholism rates, groups of substance abusers report higher rates of physical abuse than does the general population. Research predominantly involving male inpatients also suggests that physically abused subjects may demonstrate more specific substance-abusing behaviors (e.g., alcohol-use disorders, alcohol and drug abuse, earlier onset of use, impact on life-style, and suicidal drinking) than do nonabused subjects. However, the limited sample selection (e.g., inpatients), as well as the uncontrolled variance introduced by parental alcoholism, renders these results difficult to generalize to other physically abused persons.

Physical abuse has been associated with self-injurious and suicidal behaviors, as well as emotional problems such as somatization, anxiety, depression, dissociation, and psychosis, in adult, female, inpatient and community samples. Although most studies report similar findings in male subjects, research addressing these topics has primarily been conducted on alcoholic inpatients, which limits generalization of the findings to other physically abused populations.

Little research has been conducted on the presence of interpersonal problems and academic and vocational difficulties in physically abused populations. Divorce and occupational status do not differ between physically abused and nonabused men. However, research that involves more specific interpersonal and employment variables suggests that abused groups may experience more problems in these areas than do nonabused comparison groups. The limited findings on interpersonal and vocational problems are difficult to interpret because of differences in methodology (e.g., prospective vs. retrospective studies) and subject samples (e.g., gender and inpatient vs. outpatient status), as well as the lack of well-defined, adequate measures.

\section{Summary of Moderator Variables}

A moderator variable is a qualitative or quantitative variable that "affects the direction and/or strength of the relation between an independent or predictor variable and a dependent or criterion variable" (Baron \& Kenny, 1986, p. 1174). On the basis of the preceding review, several moderator variables that may affect the relationship between physical abuse and long-term characteristics can be identified. Because the review was primarily limited to research involving adult victims of childhood physical abuse, the following discussion is not exhaustive, in that moderator variables described in other bodies of literature may also be relevant to this topic. These moderator variables are reviewed in four general classifications: maltreatment characteristics, individual factors, family factors, and environmental factors. These categories are not mutually exclusive. The interaction of multiple factors is also briefly discussed.

Maltreatment characteristics. Maltreatment characteristics include variables associated with the abusive incident ${ }^{\circledR}$. The perpetrator's gender and relationship to the victim may be important moderator variables. Physical abuse by mothers is positively correlated with severity of disciplining one's children (Herrenkohl et al, 1983), nonviolent criminal behavior (Pfouts et al., 1981), suicidal behavior, and anxiety, depression, and dissociation (Briere\& Runtz, 1988). An increased number of abusive caretakers is also positively correlated with severity of discipline provided as an adult (Herrenkohl et al., 1983).

The relationship between physical abuse and long-term characteristics may also be affected by occurrence of other forms of maltreatment (e.g., sex abuse). Subjects reporting more than one form of childhood maltreatment may demonstrate more alcohol- and drug-related problems (Brown \& Anderson, 1991), severe suicidal behavior (Mills et al., 1984), and more emotional problems (Bryer et al., 1987) than do victims of one form of maltreatment.

Other maltreatment variables - such as age at onset and at termination of abuse and duration, frequency, and severity of abuse - have not been sufficiently measured and explored in the physical-abuse literature. These variables have been shown to moderate outcomes of sexual abuse (Browne \& Finkelhor, 1986).

Individual factors. Individual factors involve variables per- 
taining specifically to the physically abused individual. For example, gender may be an important moderating factor in the relationship between physical abuse and long-term consequences. Many studies have avoided variance due to gender differences by using all-male (e.g., McCord, 1979,1983) or all-female (e.g., Briere \& Runtz, 1988) samples. Research from the dating violence literature (Marshall \& Rose, 1988,1990; Sigelman et al, 1984) presents conflicting data regarding gender differences in the relationship of childhood physical abuse to violence toward dating partners; however, these studies vary in definition and measurement of childhood physical abuse and dating violence. Another set of studies has attempted to examine gender differences in inpatient populations (Carmen et al., 1984; Mills et al., 1984). These authors present descriptive data (i.e., percentages) that indicate that abused men exhibit violent behavior more often than do abused women, whereas abused women display more self-injurious and suicidal behavior than do abused men. The data also indicate that abused men and women demonstrate different rates of emotional problems. However, these authors did not evaluate whether the differences between men and women on these variables were statistically significant. An additional problem is the confound of age at victimization, gender, and form of maltreatment in these studies. Thus, it is unclear whether differences in violence, suicide, and emotional problems are due to age, gender, form of maltreatment, or an interaction of such variables.

Another relevant individual factor involves the subjects' current age or developmental level. Although a few researchers (Carmen et al., 1984; Egeland, 1988; Egeland et al, 1988; Mills et al, 1984) included both adolescents and adults in their sample, they did not look at the relationship of current age to the behaviors assessed in their subjects. Studies that examined either adolescent samples (e.g, Cavaiola \& Schiff, 1988) or adult samples (e.g, McCord, 1979, 1983) did not address this issue either.

Biological and cognitive individual factors may moderate long-term consequences of physical abuse. Biological factors such as central nervous system injury may contribute to violence in abused adolescents (Lewis, Mallouh, \& Webb, 1989; Lewis, Moy, et al, 1985). Cognitive factors may moderate longterm consequences, such as perpetration of child abuse in adulthood. For example, abused mothers who do not abuse their children have shown higher IQ scores than do abused mothers who do (Egeland, 1988). Also, Zimrin's (1986) "survivors" of abuse tended to have higher cognitive abilities than did "non-survivors." Her definition of survivor was problematic, however, because it was subjective and based on several behaviors exhibited by subjects (e.g, emotional symptoms, sense of self-fulfillment, and academic and vocational achievement).

In addition to cognitive abilities, the emotional states of physically abused subjects may impact long-term consequences. Abusive mothers show more emotional instability, as well as depression and anxiety, than do nonabusive mothers who report a similar background of maltreatment (Egeland, 1988; Egeland et al, 1988). Psychosis may contribute to violence in physically abused adolescents (Lewis, Mallouh, \& Webb, 1989; Lewis, Moy, et al, 1985), although thought disorders have not been shown to contribute to long-term consequences in physically abused adults. Finally, research has indicated that physically abused subjects may exhibit more substance-abusing behaviors than do nonabused subjects (Brown \& Anderson, 1991; Cavaiola \& Schiff, 1988; Schaefer et al, 1988). The impact of substance abuse and related behaviors on the association of physical abuse with long-term consequences has not been examined.

Family factors. Family factors are variables involved with the families of physically abused subjects. In children and adolescents, exposure to family violence and family distress, involving primarily parent-child conflict, is associated with internalizing and externalizing behaviors and with social incompetencies (JafFe et al, 1986; Wolfe \& Mosk, 1983). In adults, parental marital violence and parental conflict are associated with violence toward others (McCord, 1983; Yesavage et al, 1983), violence toward dating partners (Bernard \& Bernard, 1983; Riggs et al, 1990), severe spouse abuse (Kalmuss, 1983), and suicidal behavior (Yesavage \& Widrow, 1985). Witnessing sibling violence or aggressing toward a sibling showed a positive relationship with self-reported violence in college students (Gully et al, 1981). Conversely, sibling aggression toward these subjects revealed a negative relationship with self-reported violence (Gully et al, 1981). Therefore, variables involving familial violence and even familial distress should be considered in the relationship of physical abuse and long-term consequences. Moreover, family variables can have either exacerbating (e.g, parental marital violence) or mitigating (e.g, sibling aggression toward the subject) effects on these relationships.

A high rate of parental substance abuse and familial psychiatric illness has been shown in abused samples (Brown \& Anderson, 1991; Carmen et al, 1984; Cavaiola \& Schiff, 1988). McCord's (1983) 30-year prospective study found that parental alcoholism and parental criminal behavior did positively correlate with subjects' vulnerability to abuse (i.e., to negative outcomes that may have resulted from abuse, such as alcoholism). Although McCord did not more specifically define what types of outcomes constitute vulnerability, this suggests that parental alcoholism and criminal behavior may be important variables to examine in the research on long-term consequences of physical abuse.

Environmental factors. Environmental factors include variables primarily "outside" of the child and the child's family. Research has shown that supportive social relationships, participation in therapy, and lower numbers of stressful events may lead to more positive outcomes in abused adults (Egeland, 1988; Egeland et al, 1988; Hunter \& Kilstrom, 1979; Riggs et al, 1990; Zimrin, 1986). Additionally, McCord (1983) noted that men that returned to school after having once terminated their education showed less vulnerability to negative outcomes possibly resulting from abuse, suggesting that school experiences may have a moderating effect on long-term consequences of physical abuse.

Low SES has been cited as a risk factor of physical abuse (Kelly, 1983; Wolfe, 1988), but the studies reviewed typically use a limited range of SES subjects or statistical procedures to control the influence of SES on the measures of interest (e.g, McCord, 1979, 1983). The moderating effect of SES on longterm consequences has not yet been investigated. Similarly, removal from a maltreating home has been found to have a posi- 
tive effect on children (Rutter, 1971, as cited in Rutter, 1979); however, the moderating effect of removal from home and other placement factors, such as the number of foster homes, on long-term consequences has not been examined.

Multiple factors. Moderator variables may interact with each other or with consequences of physical abuse in their effects on behavior. These variables may occur concurrently; for example, a coexisting diagnosis of substance abuse may exacerbate violence, suicidality, and emotional problems found in physically abused adults. Multiple factors may also occur sequentially. For example, runaway behavior of an abused youth may lead to future criminality (Garbarino, Wilson, \& Garbarino, 1986). In either case, it is difficult to determine whether the behaviors assessed are caused by physical abuse, the moderator variables outlined above, other factors, or an interaction of these variables.

\section{Future Directions}

Although much has been learned in recent years, further research that will uncover additional long-term consequences of physical abuse is necessary, particularly in the areas of nonviolent criminal behavior, interpersonal problems, and vocational difficulties. Because some studies did not discriminate among types of maltreatment in their abused groups, future studies should separate subjects with histories of different forms of maltreatment (e.g., physical abuse vs. neglect vs. combined abuse and neglect) on the basis of standardized definitions. The length of time since the last incident of maltreatment should also be measured, to determine if the behaviors assessed are long-term consequences or short-term responses to some ongoing or recent abuse. Additional characteristics of the abusive incident ${ }^{\circledR}$ (e.g., gender and relationship of perpetrator, duration, frequency, and severity) should be appropriately defined and systematically evaluated to determine their association with long-term consequences.

Research involving all types of methodologies should include operationally defined, psychometrically sound measures of maltreatment variables, outcome variables, and moderator variables. Instruments should be precise enough to detect existing differences between abused and nonabused subjects,' particularly when assessing specific emotional, interpersonal, and academic and vocational problems. To eliminate problems arising from retrospective data-collection methods, more observational measures of both the independent and dependent variables should be used. If self-report or ratings by others are used, an attempt should be made to include multiple sources of information and to validate these reports with additional, preferably more objective, measures, such as child protective service records and court reports.

Very little is known about the mechanisms through which physical abuse has long-term consequences. The initial focus on the identification of potential consequences seems essential, but it is now important for researchers to elucidate the potential mechanisms. The selection of variables and assessment devices for research on the mechanisms of influence, as well as interpretation of the findings, will be more likely to be influenced by the theoretical orientation of the researchers.
The most promising research strategies to investigate consequences of maltreatment involve the prospective methodologies, which also allow a better understanding of the mechanisms that link physical abuse and short- and long-term consequences. A model of these consequences and moderator variables needs to be developed and affirmed through longitudinal research. Unfortunately, this type of research requires several years of data collection and funding and, therefore, is not feasible for many researchers. Meanwhile, comparisons of physically abused and relevant nonabused groups should be made by means of multivariate techniques that can control for or investigate the impact of moderator variables (e.g., multiple regression). Although this research methodology cannot definitively demonstrate causal relations, it can provide important evidence regarding the differences between physically abused and nonabused subjects.

Although a variety of gaps and methodological deficits have been identified in the literature, the currently available findings indicate the varied and complex nature of the long-term consequences of physical abuse in childhood. The evidence clearly indicates a need for further understanding of the long-term consequences and the variables that moderate them, as well as strategies to prevent the negative effects of abuse. Although more attention has been directed recently to the treatment of the child victims of physical abuse (cf. Fantuzzo, 1990; Hansen et al., 1990; Walker, Bonner,\& Kaufman, 1988), further understanding of the long-term impact of such intervention is also needed.

\section{Acknowledgments}

We thank Robert P. Hawkins, Catherine A. Martin, Francis Malinosky-Rummell, and Nora S. Newcombe for their helpful comments on versions of this article.

\section{References}

Abrams, J. R. (1981). Adolescent perceptions of parental discipline and juvenile delinquency. In R. J. Hunner \& Y. E. Walker (Eds.), Exploring (he relationship between child abuse and delinquency (pp. 252-265). Montclair, NJ: Allanheld, Osmun.

Alfaro, J. D. (1981). Report on the relationship between child abuse and neglect and later socially deviant behavior. In R. J. Hunner \& Y. E. Walker (Eds.), Exploring the relationship between child abuse and delinquency (pp. 175-219). Montclair, NJ: Allanheld, Osmun.

Ammerman, R. T., Cassisi, J. E., Hersen, M., \& Van Hasselt, V B. (1986). Consequences of physical abuse and neglect in children. Clinical Psychology Review, 6, 291-310.

Baron, R. M., \& Kenny, D. A. (1986). The moderator-mediator variable distinction in social psychological research: Conceptual, strategic, and statistical considerations. Journal of Personality and Social Psychology, 51, 1173-1182.

Bernard, M. L., \& Bernard, J. L. (1983). Violent intimacy: The family as a model for love relationships. Family Relations, 32, 283-286.

Blount, H. R., \& Chandler, T. Z. (1979). Relationship between childhood abuse and assaultive behavior in adolescent male psychiatric patients. Psychological Reports, 44, 11-26.

Briere, J., \& Runtz, M. (1988). Multivariate correlates of childhood psychological and physical maltreatment among university women. Child Abuse and Neglect, 12, 331-341.

Briere, J., \& Runtz, M. (1990). Differential adult symptomatology asso- 
ciated with three types of child abuse histories. Child Abuse and Neglect, 14, 357-364.

Brown, G. R., \& Anderson, B. (1991). Psychiatric morbidity in adult inpatients with childhood histories of sexual and physical abuse. American Journal of Psychiatry, 148, 55-61.

Browne, A., \& Finkelhor, D. (1986). Impact of child sexual abuse: A review of the research. Psychological Bulletin, 99, 66-77.

Bryer, J. B., Nelson, B. A., Miller, J. B., \& Krol, R A. (1987). Childhood sexual and physical abuse as factors in adult psychiatric illness. American Journal of Psychiatry, 144, 1426-1430.

Carmen, E. H., Rieker, P. P., \& Mills, T. (1984). Victims of violence and psychiatric illness. American Journal of Psychiatry, 141, 378383.

Cavaiola, A. A., \& Schiff, M. (1988). Behavioral sequelae of physical and/or sexual abuse in adolescents. Child Abuse and Neglect, 12, $181-188$.

Chu, J. A., \& Dill, D. L. (1990). Dissociative symptoms in relation to childhood physical and sexual abuse. American Journal of Psychiatry, 147, 887-892.

Cohen, F. S., \& Densen-Gerber, J. (1982). A study of the relationship between child abuse and drug addiction in 178 patients: Preliminary results. Child Abuse and Neglect, 6, 383-387.

Conaway, L. P., \& Hansen, D. J. (1989). Social behavior of physically abused and neglected children: A critical review. Clinical Psychology Review, 9, 627-652.

Deykin, E. Y., Alpert, J. J., \& McNamarra, J. J. (1985). A pilot study of the effect of exposure to child abuse or neglect on adolescent suicidal behavior. American Journal of Psychiatry, 142, 1299-1303.

Egeland, B. (1988). Breaking the cycle of abuse: Implications for prediction and intervention. In K. D. Browne, C. Davies, \& P. Stratton (Eds.), Early prediction and prevention of child abuse. New York: Wiley.

Egeland, B., Jacobvitz, D., \& Sroufe, L. A. (1988). Breaking the cycle of abuse. Child Development, 59, 1080-1088.

Fantuzzo, J. W. (1990). Behavioral treatment of the victims of child abuse and neglect. Behavior Modification, 14, 316-339.

Fitch, F. J., \& Papantonio, A. (1983). Men who batter: Some pertinent characteristics. Journal of Nervous and Mental Disease, 171, 190192.

Garbarino, J., \& Plantz, M. C. (1986). Child abuse and juvenile delinquency: What are the links? In J. Garbarino, C. J. Schellenbach, \& J. M. Sebes (Eds.), Troubled youth, troubled families (pp. 27-39). New York: Aldine de Gruyter.

Garbarino, J., Wilson, J., \& Garbarino, A. C. (1986). The adolescent runaway. In J. Garbarino, C. J. Schellenbach, \& J. M. Sebes (Eds.), Troubled youth, troubled families (pp. 41-54). New York: Aldine de Gruyter.

Gully, K. J., Dengerink, H. A., Pepping, M., \& Bergstrom, D. (1981). Research note: Sibling contribution to violent behavior. Journal of Marriage and the Family, 43, 333-337.

Hansen, D. J., Conaway, L. P., \& Christopher, J. S. (1990). Victims of child physical abuse. In R. T. Ammerman \& M. Hersen (Eds.), Treatment of family violence: A sourcebook (pp. 17-49). New York: Wiley.

Herrenkohl, E. C., Herrenkohl, R. C., \& Toedter, L. J. (1983). Perspectives on the intergenerational transmission of abuse. In D. Finkelhor, R. J. Gelles, G. T. Hotaling, \& M. A. Straus (Eds.), The dark side of families: Current family violence research (pp. 305-316). Beverly Hills, CA: Sage.

Hjorth, C. W., \& Ostrov, E. (1982). The self-image of physically-abused adolescents. Journal of Youth and Adolescence, 11, 71-76.
Hunter, R. S., \& Kilstrom, N. (1979). Breaking the cycle in abusive families. American Journal of Psychiatry, 136, 1320-1322.

Jaffe, P., Wolfe, D., Wilson, S., \& Zak, L. (1986). Similarities in behavioral and social maladjustment among child victims and witnesses to family violence. American Journal of Orthopsychiatry, 56, 142 146.

Kalmuss, D. (1984). The intergenerational transmission of marital aggression. Journal of Marriage and the Family, 46, 11-19.

Kashani, J. H., Shekim, W. O., Burk, J. P., \& Beck, N. C. (1987). Abuse as a predictor of psychopathology in children and adolescents. Journal of Clinical Child Psychology, 16, 43-50.

Kaufman, J., \& Zigler, E. (1987). Do abused children become abusive parents? American Journal of Orthopsychiatry, 57, 186-192.

Kelly, J. A. (1983). Treating child-abusive families: Intervention based on skills-training principles. New York: Plenum Press.

Kempe, C. H., Silverman, H., Steele, B., Droegemueller, W., \& Silver, H. (1962). The battered child syndrome. Journal of the American Medical Association, 181, 17-24.

Kent, J. T. (1976). A follow-up study of abused children. Journal of Pediatric Psychology, 1, 25-31.

Kroll, P. D., Stock, D. F, \& James, M. E. (1985). The behavior of adult alcoholic men abused as children. Journal of Nervous and Mental Disease, 173, 689-693.

Lamphear, V. S. (1985). The impact of maltreatment on children's psychosocial adjustment: A review of the research. Child Abuse and Neglect, 9, 251-263.

Lane, T. W., \& Davis, G. E. (1987). Child maltreatment and juvenile delinquency: Does a relationship exist? In J. D. Burchard \& S. N. Burchard (Eds.), Prevention of delinquent behavior (pp. 122-138). Newbury Park, CA: Sage.

Laner, M. R., \& Thompson, J. (1982). Abuse and aggression in courting couples. Deviant Behavior, 3, 229-244.

Lewis, D. O., Mallouh, C., \& Webb, V. (1989). Child abuse, delinquency, and violent criminality. In D. Cicchetti \& V. Carlson (Eds.), Child maltreatment: Theory and research on the causes and consequences of child abuse and neglect (pp. 707-721). Cambridge, England: Cambridge University Press.

Lewis, D. O., Moy, E., Jackson, L. D., Aaronson, R., Restifo, N., Serra, S., \& Simos, A. (1985). Biopsychosocial characteristics of children who later murder: A prospective study. American Journal of Psychiatry, 142, 1161-1167.

Lewis, D. O., Shanok, S. S., \& Balla, D. A. (1979). Perinatal difficulties, head and fact trauma, and child abuse in the medical histories of seriously delinquent children. American Journal of Psychiatry, 136, 419-423.

Lewis, D. O., Shanok, S. S., Pincus, J. H., \&Glaser, G. H. (1979). Violent juvenile delinquents: Psychiatric, neurological, psychological, and abuse factors. Journal of the American Academy of Child Psychiatry, 18, 307-319.

Marshall, L. L., \& Rose, P. (1988). Family of origin violence and courtship violence. Journal of Counseling and Development, 66, 414418.

Marshall, L. L., \& Rose, P. (1990). Premarital violence: The impact of family of origin violence, stress, and reciprocity. Violence and Victims, 5, 51-64.

McCord, J. (1979). Some child-rearing antecedents of criminal behavior in adult men. Journal of Personality and Social Psychology, 37, $1477-1486$.

McCord, J. (1983). A forty year perspective on the effects of child abuse and neglect. Child Abuse and Neglect, 7, 265-270.

Mills, T, Rieker, P. P., \& Carmen, E. H. (1984). Hospitalization experi- 
ences of victims of abuse. Victimology: An International Journal, 9, 439-449.

Monane, M., Leichter, D., \& Lewis, D. O. (1984). Physical abuse in psychiatrically hospitalized children and adolescents. Journal of the American Academy of Child Psychiatry; 23, 653-658.

National Center on Child Abuse and Neglect. (1988). Study of national incidence and prevalence of child abuse and neglect: 1988. Washington, DC: U.S. Department of Health and Human Services.

Pfouts, J. H., Schopler, J. H., \& Henley, H. C. (1981). Deviant behaviors of child victims and bystanders in violent families. In R. J. Hunner \& Y. E. Walker (Eds.), Exploring the relationship between child abuse and delinquency (pp. 79-99). Montclair, NJ: Allanheld, Osmun.

Pollock, V. E., Briere, J., Schneider, L., Knop, J., Mednick, S. A., \& Goodwin, D. W. (1990). Childhood antecedents of antisocial behavior: Parental alcoholism and physical abusiveness. American Journal of Psychiatry, 147, 1290-1293.

Putnam, F. W., Guroff, J. J., Silberman, E. K., Barban, L., \& Post, R. M. (1986). The clinical phenomenology of multiple personality disorder: Review of 100 recent cases. Journal of Clinical Psychiatry, 47, 285-293.

Reuterman, N. A., \& Burcky, W. D. (1989). Dating violence in high school: A profile of the victims. Psychology: A Journal of Human Behavior, 26, 1-9.

Riggs, D. S., O’Leary, K. D., \& Breslin, F. C. (1990). Multiple correlates of physical aggression in dating couples. Journal of Interpersonal Violence, 561-73.

Rogeness, G. A., Amrung, S. A., Macedo, C. A., Harris, W. R., \& Fisher, C. (1986). Psychopathology in abused or neglected children. Journal of the American Academy of Child Psychiatry, 25, 659665.

Rogers, S., \& LeUnes, A. (1979). A psychometric and behavioral comparison of delinquents who were abused as children with their nonabused peers. Journal of Clinical Psychology, 35, 470-472.

Roscoe, B., \& Benaske, N. (1985). Courtship violence experienced by abused wives: Similarities in patterns of abuse. Family Relations, 34, 419-424.

Roscoe, B., \& Callahan, J. E. (1985). Adolescents' self-report of violence in families and dating relations. Adolescence, 20, 545-553.

Rosenbaum, A., \& O'Leary, K. D. (1981). Marital violence: Characteristics of abusive couples. Journal of Consulting and Clinical Psychology, 49, 63-71.

Rosenbaum, M., \& Bennett, B. (1986). Homicide and depression. American Journal of Psychiatry, 143, 367-370.

Rounsaville, B. J., Weissman, M. M., Wilber, C. H., \& Kleber, H. D. (1982). Pathways to opiate addiction: An evaluation of differing antecedents. British Journal of Psychiatry, 141, 437-446.

Rutter, M. (1979). Maternal deprivation, 1972-1978: New findings, new concepts, new approaches. Child Development, 50, 283-305.

Sack, W. H., \& Mason, R. (1980). Child abuse and conviction of sexual crimes: A preliminary finding. Law and Human Behavior, 4, 211215.

Schaefer, M. R., Sobieraj, K., \& Hollyfield, R. L. (1988). Prevalence of childhood physical abuse in adult male veteran alcoholics. Child Abuse and Neglect, 12, 141-149.

Sendi, I. B., \& Blomgren, P. G. (1975).A comparative study of predictive criteria in the predisposition of homicidal adolescents. American Journal of Psychiatry, 132, 423-427.

Sigelman, C. K., Berry, C. J., \& Wiles, K. A. (1984). Violence in college students' dating relationships. Journal of Applied Social Psychology, 14, 530-548.

Straus, M. A., Gelles, R. J., \& Steinmetz, S. K. (1980). Behind closed doors: Violence in the American family. Garden City, NY: Anchor Press.

Tarter, R. E., Hegedus, A. M., Winsten, N. E., \& Alterman, A. I. (1984). Neuropsychological, personality, and familial characteristics of physically abused delinquents. Journal of the American Academy of Child Psychiatry, 23, 668-674.

Tupin, J. P., Mahar, D., \& Smith, D. (1973). Two types of violent offenders with psychosocial descriptors. Diseases of the Nervous System, 34, 356-363.

Walker, C. E., Bonner, B. L., \& Kaufman, K. L. (1988). The physical$l y$ and sexually abused child: Evaluation and treatment. New York: Pergamon Press.

Widom, C. S. (1989). Does violence beget violence? A critical examination of the literature. Psychological Bulletin, 106, 3-28.

Wolfe, D. A. (1988). Child abuse and neglect. In E. J. Mash \& L. G. Terdal (Eds.), Behavioral assessment of childhood disorders (pp. 627-669). New York: Guilford Press.

Wolfe, D. A., \& Mosk, M. D. (1983). Behavioral comparisons of children from abusive and distressed families. Journal of Consulting and Clinical Psychology, 51, 702-708.

Yesavage, J. A., Becker, M. T., Werner, P. D., Patton, M. J., Seeman, K., Brunsting, D. W., \& Mills, M. A. (1983). Family conflict, psychopathology, and dangerous behavior by schizophrenic inpatients. Psychiatry Research, 8, 271-280.

Yesavage, J. A., \& Widrow, L. (1985). Early parental discipline and adult self-destructive acts. Journal of Nervous and Mental Disease, 17, 14-77.

Zimrin, H. (1986). A profile of survival. Child Abuse and Neglect, 10, 339-349. 